\title{
Relationship Between Mainstream Cigarette Smoke "Tar" and Nicotine Yields *
}

\author{
by Michael J. Morton ${ }^{1}$, Susan W. Laffoon ${ }^{1}$, Peter J. Lipowicz ${ }^{1}$, and Jeffrey I. Seeman ${ }^{2}$ \\ ${ }^{1}$ Altria Client Services Inc., 601 E. Jackson, Richmond, VA 23219, USA \\ ${ }^{2}$ SaddlePoint Frontiers, 12001 Bollingbrook Place, Richmond, VA 23236, USA
}

\section{SUMMARY}

The purpose of this research was to examine the relationship between mainstream "tar" and nicotine yields and refine the commonly used linear model with a positive intercept to incorporate non-linearity and product-toproduct differences in filler nicotine content. "Tar" and nicotine yields are examined for a wide range of cigarettes (U.S. and international) using the Cambridge filter (CF), ISO, and the more intense MDPH, and HC smoking methods. Particularly at very low machine yields, a nonlinearity is observed that can be more accurately modeled by a power law relationship, and can be further improved by incorporating the concentration of nicotine in the cigarette filler into the equation. The resultant power law relationship is the better statistical fit to the available data, avoids the physical implausibility of positive nicotine yield at zero "tar" yield and lack of dependence on filler nicotine that are inherent in the simple linear model relating nicotine yield to "tar" yield alone, and explains the nonconstancy of the "tar"-to-nicotine ratio. The relationship between "tar" and nicotine can be affected by the use of very long or very short puff intervals, and, with the same tobacco blend and the same "tar" yield, longer cigarettes tend to have a slightly higher nicotine yield than shorter cigarettes. [Beitr. Tabakforsch. Int. 25 (2013) 671-684]

\section{ZUSAMMENFASSUNG}

Gegenstand dieser Forschungsarbeit war die Untersuchung des Zusammenhangs zwischen den Teer- und Nikotinausbeuten im Hauptstromrauch und die Optimierung des häufig verwendeten linearen Modells durch einen positiven Achsenabschnitt, um die nichtlinearen Unterschiede zwi- schen den Produkten hinsichtlich des Nikotingehalts des Füllstoffs zu berücksichtigen. Die Teer- und Nikotinausbeuten werden bei einer Vielzahl von (US-amerikanischen und internationalen) Zigaretten mit dem Cambridge Filter (CF) durch die Bestimmungsverfahren ISO und die intensiveren Methoden MDPH und $\mathrm{HC}$ untersucht. Insbesondere bei sehr niedrigen maschinellen Ausbeuten ist eine Nichtlinearität zu beobachten, die durch eine Potenzfunktion genauer modelliert werden kann und durch Einbeziehung der Nikotinkonzentration im Zigarettenfüllstoff in die Gleichung weiter verbessert werden kann. Die sich daraus ergebende Potenzfunktion passt statistisch besser zu den verfügbaren Daten, vermeidet die physikalische Unplausibilität einer positiven Nikotinausbeute bei einer Teerausbeute von Null und die mangelnde Abhängigkeit vom Nikotin im Füllstoff, die dem einfachen linearen Modell innewohnen, in welchem die Nikotinausbeute nur zur Teerausbeute in Beziehung gesetzt wird. Zudem erklärt sie die Nichtkonsistenz des Verhältnisses von Teer zu Nikotin. Die Beziehung zwischen Teer und Nikotin kann durch die Verwendung von sehr langen oder sehr kurzen Abständen zwischen den Zügen beeinflusst werden. Mit derselben Tabakmischung und derselben Teerausbeute haben längere Zigaretten tendenziell eine leicht höhere Nikotinausbeute als kürzere Zigaretten. [Beitr. Tabakforsch. Int. 25 (2013) 671-684]

\section{RESUME}

L'objectif de cette recherche était d'étudier la relation entre le goudron du flux de fumé principal et les teneurs en nicotine et de perfectionner le modèle linéaire généralement utilisé avec une interception positive permettant d'incorporer des différences de non-linéarité et entre diffé- 
rents produits dans la teneur en nicotine de la matière de remplissage. Les teneurs en goudron et en nicotine sont étudiées pour une vaste gamme de cigarettes (des USA et d'origine internationale) utilisant le filtre Cambridge (CF), le régime de fumage ISO ainsi que les régimes de fumage plus intenses du MDPH et de HC. On observe en particulier une non-linéarité à des teneurs machine très faibles, qui peut être modelée avec plus de précision par une relation de loi de puissance et peut être encore améliorée en incorporant dans l'équation la concentration de nicotine dans la matière de remplissage de la cigarette. La relation de loi de puissance en résultant est la meilleure réponse statistique aux données disponibles, elle évite l'implausibilité physique d'une teneur en nicotine positive avec une teneur en goudron zéro et un manque de dépendance à la nicotine de la matière de remplissage qui sont inhérents dans le modèle linéaire simple n'associant la teneur en nicotine qu'à la teneur en goudron, et elle explique la nonconstance du rapport du goudron à la nicotine. La relation entre le goudron et la nicotine peut être affectée par l'utilisation d'intervalles de bouffées très longues ou très courtes et, avec le même mélange de tabac et la même teneur en goudron, les cigarettes plus longues ont tendance à avoir une teneur en nicotine légèrement plus élevée que les cigarettes plus courtes. [Beitr. Tabakforsch. Int. 25 (2013) 671-684]

\section{KEY WORDS}

Tobacco; cigarette; mainstream smoke; nicotine; "tar"; machine-smoking; "tar"-to-nicotine ratio

\begin{tabular}{ll}
\hline Abbreviations & \\
\hline CF & Cambridge filter \\
MS & Mainstream \\
MDPH & Massachussetts Department of Public Health \\
HC & Health Canada \\
TITL & Tobacco Industry Testing Laboratory \\
HPHC & Harmful and Potentially Harmful Constituents \\
TSNA & Tobacco-specific nitrosamines \\
TPM & Total particulate matter \\
RH & Relative humidity \\
\hline
\end{tabular}

\section{INTRODUCTION}

The effects of cigarette design, ingredients, additives, and tobacco blends on the chemical, physical, and biological properties of mainstream (MS) and sidestream (SS) cigarette smoke is a major area of study (see 1-22, 65, 66). In these and many other reports, machine-smoking methods remain among the primary experimental techniques of choice even though it has been known for decades that no single method can model the various ways that humans smoke cigarettes (23-27, 66-69). In the United States, Canada, and other countries, cigarette manufacturers are required to provide MS smoke nicotine and/or "tar" yields using one of several machine-smoking methods. Those machine yields have been examined to investigate overtime trends in cigarette nicotine yields (28). In addition, machine-smoking methods are used in benchmark studies in which MS smoke yields of various constituents are predicted based on the yields of nicotine or "tar" or carbon monoxide (5-7, 29-32). Machine-smoking methods continue to be used (see 12, 19, 28, 33-35) and continue to play a central role in both the short term and long term strategic plans of the public health community (36-38). Nonetheless, these methods are best viewed as useful complements to human-smoking exposure studies and in vitro or in vivo toxicological studies $(36,38)$.

Nicotine in cigarette smoke is generally related to "tar" yield in commercial cigarettes in a roughly linear manner $(5-7,29,30,32,39-42)$. Some have refined that relationship through the incorporation of the nicotine concentration of the cigarette filler $(31,42)$. Researchers have proposed similar models for other smoke constituents such as tobacco-specific nitrosamines (TSNAs) and a somewhat different approach was taken by HARRIS (70). COUNTS et al. (6) incorporated the weight or the amount (e.g., nanograms per cigarette) of the TSNAs in the cigarette to improve the fit of the corresponding TSNAs in smoke. COUNTS et al. (7) and MORTON and LAFFOON (31) utilized the concentration of the TSNA (e.g., measured in nanograms per gram of cigarette filler). In the U.S., cigarette companies were required in 2012 by the FDA to report the weight per cigarette (not the concentration) of each of six harmful and potentially harmful (HPHC) cigarette filler constituents, including nicotine. To our knowledge no researcher has explicitly compared the relative utility of these two ways of quantifying the constituent content of the cigarette filler, i.e. weight or concentration, they have simply used or required one or the other.

The purpose of this research was to examine the relationship between nicotine yield and "tar" yield in many different machine-smoking settings and refine the commonly estimated, but implausible, linear model with a non-zero intercept. This also involves an explicit comparison of whether weight of nicotine in the cigarette or concentration of nicotine in the cigarette filler is better for use in modeling the nicotine yield of the cigarette.

\section{METHODS}

The four commonly used machine-smoking protocols discussed in this paper are:

1. Cambridge filter $(\mathrm{CF}$; formerly also known as the FTC method) using $35 \mathrm{cc}$ puffs, taken once per minute, with no blocking of the cigarette ventilation holes (43);

2. ISO using $35 \mathrm{cc}$ puffs, taken once per minute, with no blocking of the cigarette ventilation holes $(44,45)$. There are subtle differences between the ISO and CF smoking methods, but the smoke yields are typically quite similar;

3. Massachusetts Department of Public Health (MDPH) using 45 cc puffs, taken twice per minute with $50 \%$ of the ventilation holes blocked (46);

4. Health Canada Intense (HC) using 55 cc puffs, taken twice per minute, with $100 \%$ of the ventilation holes blocked (47).

The data sets used are:

1. FTC market samples data from 1967 to 2008 (see Table 1). There were 51 market samples during that time. 
Table 1. FTC/TITL market samples

\begin{tabular}{|c|c|c|c|}
\hline Year & Date of Pickup & $\begin{array}{c}\text { Market } \\
\text { Samples }\end{array}$ & $\mathrm{N}$ \\
\hline 1967 & $\begin{array}{r}9 / 67 \\
8 / 67-1 / 68\end{array}$ & $\begin{array}{l}\text { MS \#1 } \\
\text { MS \#2 }\end{array}$ & 127 \\
\hline 1968 & $\begin{array}{r}8 / 67-1 / 68 \\
6 / 68^{*} \\
10 / 68^{*}\end{array}$ & $\begin{array}{l}\text { MS \#2 } \\
\text { MS \#3 } \\
\text { MS \#4 }\end{array}$ & 137 \\
\hline 1969 & $\begin{array}{r}3 / 69 \\
7 / 69 \\
12 / 69-1 / 70\end{array}$ & $\begin{array}{l}\text { MS \#5 } \\
\text { MS \#6 } \\
\text { MS \#7 }\end{array}$ & 127 \\
\hline 1970 & $\begin{array}{r}12 / 69-1 / 70 \\
5 / 70-6 / 70 \\
12 / 70-1 / 71\end{array}$ & $\begin{array}{l}\text { MS \#7 } \\
\text { MS \#8 } \\
\text { MS \#9 }\end{array}$ & 131 \\
\hline 1971 & $\begin{array}{r}12 / 70-1 / 71 \\
10 / 71^{*}\end{array}$ & $\begin{array}{c}\text { MS \#9 } \\
\text { MS \#10 }\end{array}$ & 134 \\
\hline 1972 & $\begin{array}{l}1 / 72 \\
6 / 72\end{array}$ & $\begin{array}{l}\text { MS \#11 } \\
\text { MS \#12 }\end{array}$ & 145 \\
\hline 1973 & $\begin{array}{l}1 / 73 \\
9 / 73\end{array}$ & $\begin{array}{l}\text { MS \#13 } \\
\text { MS \#14 }\end{array}$ & 136 \\
\hline 1974 & $\begin{array}{r}3 / 74 \\
9 / 74-10 / 74\end{array}$ & $\begin{array}{l}\text { MS \#15 } \\
\text { MS \#16 }\end{array}$ & 148 \\
\hline 1975 & $\begin{array}{r}3 / 75-5 / 75 \\
8 / 75-10 / 75\end{array}$ & $\begin{array}{l}\text { MS \#17 } \\
\text { MS \#18 }\end{array}$ & 147 \\
\hline 1976 & $\begin{array}{l}5 / 76^{*} \\
11 / 76\end{array}$ & $\begin{array}{l}\text { MS \#19 } \\
\text { MS \#20 }\end{array}$ & 180 \\
\hline 1977 & $5 / 77-7 / 77$ & MS \#21 & 167 \\
\hline 1979 & $\begin{array}{r}4 / 79 \\
10 / 79-11 / 79\end{array}$ & $\begin{array}{l}\text { MS \#23 } \\
\text { MS \#24 }\end{array}$ & 190 \\
\hline 1981 & $\begin{array}{r}3 / 81-4 / 81 \\
12 / 81-2 / 82\end{array}$ & $\begin{array}{l}\text { MS \#25 } \\
\text { MS \#26 }\end{array}$ & 214 \\
\hline 1982 & $\begin{array}{l}12 / 81-2 / 82 \\
8 / 82-12 / 82\end{array}$ & $\begin{array}{l}\text { MS \#26 } \\
\text { MS \#27 }\end{array}$ & 225 \\
\hline 1983 & $10 / 83-1 / 84$ & MS \#28 & 205 \\
\hline 1986 & $1986^{*}$ & MS \#29 & 256 \\
\hline 1987 & $1987^{*}$ & MS \#30 & 273 \\
\hline 1988 & 1988 & MS \#31 & 278 \\
\hline 1989 & 1989 & MS \#32 & 307 \\
\hline
\end{tabular}

* Estimated

\# Supplemented with PM USA data

These data were obtained from FTC Reports, TITL reports, and/or TITL spreadsheets. The market samples were assigned to years as shown in Table 1. Note that there are different conventions in different years related to the reporting of very low yield products. In several years, we only had available to us an indication that values were below some threshold (e.g., "tar" < $0.5 \mathrm{mg}$ ). In other years we had available to us a value, even if extremely low. We used the very low values if they were available, but omitted the small number of values listed as negative. Some additional products tested by Philip Morris USA (PM USA) for reporting to the FTC were also included as indicated in Table 1.

2. For market samples from 1981, 1995, and 1996 tobacco filler nicotine analyses for many of the products were available from internal PM USA analyses and were combined with the market sample data. For 1992, inter-

\begin{tabular}{|c|c|c|c|}
\hline Year & Date of Pickup & $\begin{array}{l}\text { Market } \\
\text { Samples }\end{array}$ & $\mathrm{N}$ \\
\hline 1990 & $3 / 90-4 / 90$ & MS \#33 & 337 \\
\hline 1991 & $3 / 91-4 / 91$ & MS \#34 & 384 \\
\hline 1992 & $2 / 92-3 / 92$ & MS \#35 & 413 \\
\hline 1993 & $2 / 93-4 / 93$ & MS \#36 & 482 \\
\hline 1994 & $1 / 94-2 / 94$ & MS \#37 & 516 \\
\hline 1995 & $1 / 95-2 / 95$ & MS \#38 & 523 \\
\hline 1996 & $1 / 96-2 / 96$ & MS \#39 & 518 \\
\hline 1997 & $1 / 97^{*}$ & MS \#40 & 518 \\
\hline 1998 & $1 / 98^{*}$ & MS \#41 & 507 \\
\hline 1999 & $1 / 99^{*}$ & MS \#42 & 526 \\
\hline 2000 & $1 / 00^{*}$ & MS \#43 & 518 \\
\hline 2001 & $1 / 01^{*}$ & MS \#44 & $617^{\#}$ \\
\hline 2002 & $1 / 02^{*}$ & MS \#45 & $627^{\#}$ \\
\hline 2003 & $1 / 03$ & MS \#46 & $576^{\#}$ \\
\hline 2004 & $1 / 04-2 / 04$ & MS \#47 & $542^{\#}$ \\
\hline 2005 & $1 / 05-2 / 05^{*}$ & MS \#48 & 428 \\
\hline 2006 & $1 / 06-2 / 06$ & MS \#49 & 421 \\
\hline 2007 & $1 / 07-8 / 07$ & MS \#50 & 517 \\
\hline 2008 & $1 / 08-7 / 08$ & MS \#51 & 531 \\
\hline
\end{tabular}

nal PM USA "tar", nicotine, and tobacco filler nicotine data were available for many products.

3. A set of 48 PM USA and Philip Morris International commercial products machine-smoked using the ISO, $\mathrm{MDPH}$, and $\mathrm{HC}$ smoking protocols and reported in COUNTS et al. (7).

4. Internal product data for two PM USA products for the years 2003 and 2004.

5. A single PM USA product smoked using multiple puff profiles to give a wide "tar" range and reported in MORTON et al. (48).

6. The high alkaloid data from Table 1 of St. CHARLES et al. (42).

7. Data generated by PM USA for reporting to the state of Massachusetts from 1997-2010 using the MDPH smoking protocol. 
Only cigarettes that have been equilibrated at $60 \% \mathrm{RH}$ are examined in this paper. This minimizes the effect of tobacco moisture on the cigarette yields. It has been shown that moisture can affect the nicotine and "tar" relationship, with drier cigarettes tending to yield more nicotine at the same "tar" yield (48-52).

\section{RELATIONSHIPS BETWEEN MS SMOKE NICOTINE YIELDS AND "TAR" YIELDS}

\subsection{Linear relationships between MS smoke nicotine yields and "tar" yields}

Figure 1 illustrates the typical relationship between MS smoke nicotine and "tar" for U.S. commercial cigarettes using the CF machine-smoking method with the data from
Market Sample \#51 conducted in 2008 by the Tobacco Industry Testing Laboratory (TITL). The graph illustrates four points:

- The relationship is approximately linear;

- There are "outlier" points, i.e., cigarette products that fall outside the general relationship. In this instance, there are two "outlier" points corresponding to Eclipse cigarettes;

- The spread around the regression line increases the higher the "tar" yield. This has been noted before and has been accounted for by applying weighted regression using 1/"tar" as the weighting factor (see 7);

- There is a positive intercept and the products with very low "tar" yield are all below the regression line. That the low "tar" yield data points are all below the regression line indicates that the linear fit can be improved upon. We return to this point in section 3.2 below.

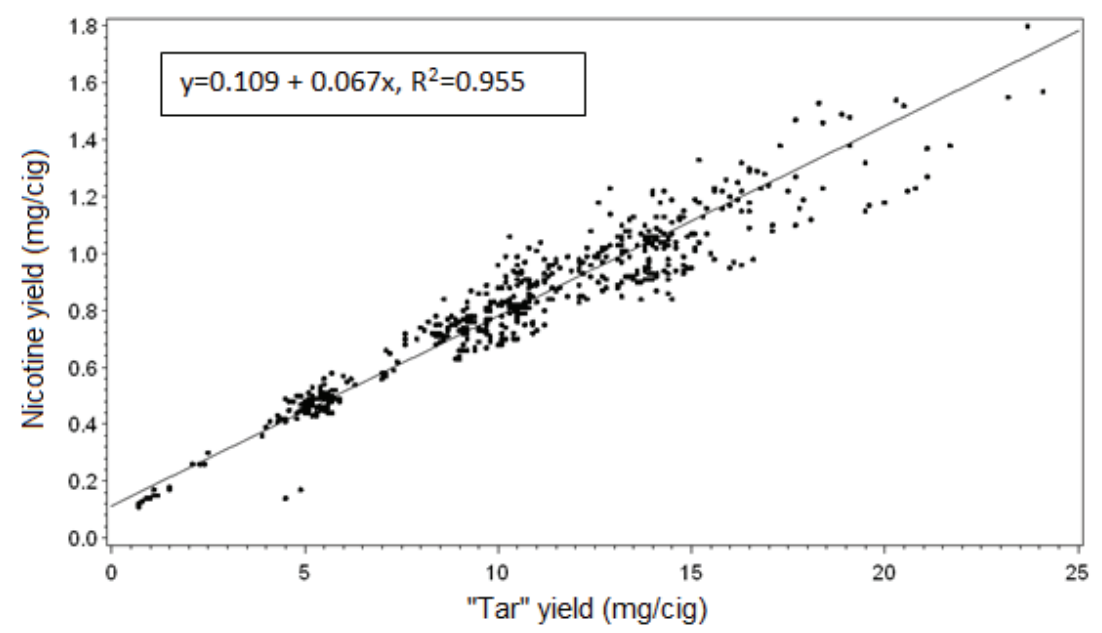

Figure 1. Linear relationship between MS smoke nicotine versus "tar" for U.S. commercial cigarettes in Market Sample \#51 sampled and tested in 2008 using the CF machine-smoking method.

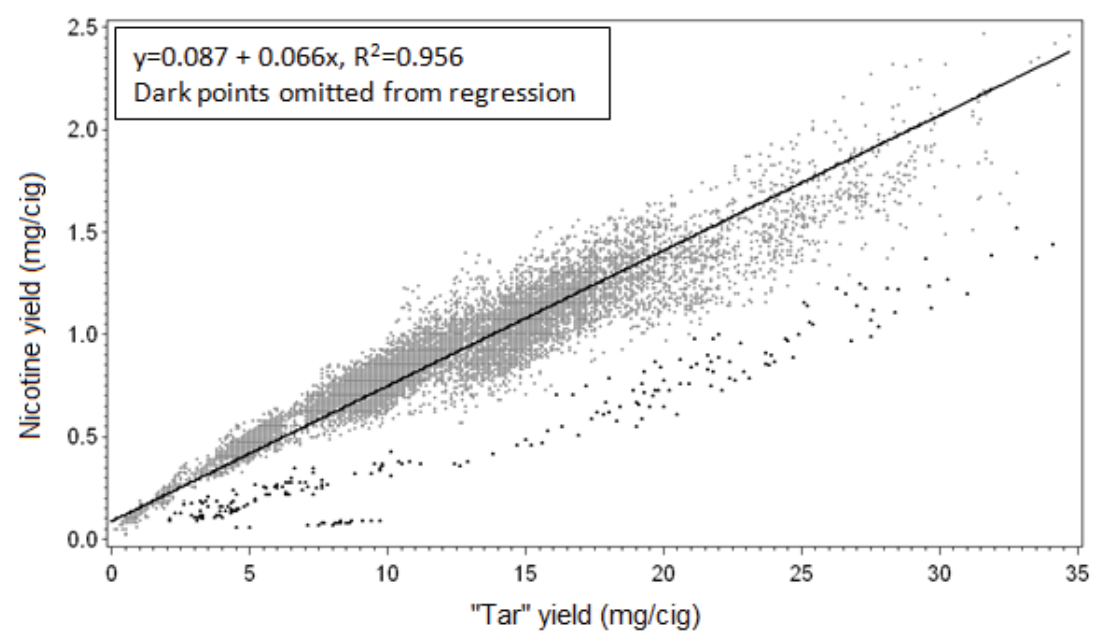

Figure 2. All market samples from 1967 to 2008. The regression equation and $\mathrm{R}^{2}$ calculation exclude the 215 "outlier" points highlighted in the graph. 
Figure 2 shows the data from 13,027 data points from the 51 market samples conducted from 1967 to 2008. The majority of the data shows a similar pattern to that observed with Figure 1. The linear regression across the entire time period is very similar to that found in 2008. Additionally, we see a small collection of data points with nicotine yields below the general population. The lowest of the data points correspond to products using de-nicotinized tobaccos such as the PM USA product Next. Other data points below the population consist of products, such as Sano, Domino, Vogue, Mapleton, and others, that were either blended to be low nicotine or used partially denicotinized tobaccos. The regression line in the graph does not include the 215 "outlier" data points highlighted in the graph.

The equations relating "tar" and nicotine from year-to-year are generally similar, though the small year-to-year differences (not shown) are statistically significant. The year-toyear variation was taken into account by fitting a random coefficients model to the data (see 53, 54). As noted above, the scatter around the line tends to increase at higher yields and this was accounted for through the use of weighted regression using $1 /$ "tar" as the weighting factor. The resulting fitted equation is:

Nicotine $=0.066 \times$ "tar" +0.087

The weighted $\mathrm{R}^{2}$ for the model is 0.956 .

Figure 3 shows "tar" and nicotine yields from 48 PM USA and Philip Morris International products each tested under ISO, MDPH, and HC smoking protocols. The linear equation shown with the data is equation [1] and is very close to the equation that would be fitted to this data set. This shows that the relationship fit under CF or ISO conditions extrapolates reasonably well to more intense smoking conditions. Though not shown here, this also holds true with products in the so-called MASSACHUSSETTS BENCHMARK STUDY (29).
Each of the previous graphs showed many different products machine-smoked either using a single protocol or using three different protocols. We next examined data from MORTON et al. (48), in which a single product is smoked in 16 different ways (see Table 2). The intent was to generate similar "tar" yields using three different puff volumes by changing the interpuff interval (and in two instances by removing the product from the smoking machine after a designated number of puffs). The interpuff interval is defined here as the time from the start of one puff until the start of the next puff.

Table 2. MS smoke nicotine and "tar" yields for a U.S. commercial cigarette using machine-smoking methods with a 2-s puff and inter-puff intervals and puff volumes as listed.

\begin{tabular}{l|c|c|c}
\hline Puff volume & Puff interval & $\begin{array}{c}\text { "Tar" } \\
(\mathrm{mg} / \mathrm{cig})\end{array}$ & $\begin{array}{c}\text { Nicotine } \\
(\mathrm{mg} / \mathrm{cig})\end{array}$ \\
\hline $35 \mathrm{cc}$ & $130 \mathrm{~s}$ & 6 & 0.4 \\
& $60 \mathrm{~s}$ & 11 & 0.8 \\
& $35 \mathrm{~s}$ & 16 & 1.2 \\
& $19 \mathrm{~s}$ & 22 & 1.5 \\
$55 \mathrm{cc}$ & $9 \mathrm{~s} \#$ & 31 & 1.7 \\
& $166 \mathrm{~s}$ & 7 & 0.4 \\
& $92 \mathrm{~s}$ & 12 & 0.8 \\
& $61 \mathrm{~s}$ & 16 & 1.1 \\
$70 \mathrm{cc}$ & $39 \mathrm{~s}$ & 21 & 1.5 \\
& $23 \mathrm{~s}$ & 30 & 2.0 \\
& $180 \mathrm{~s}(2 \mathrm{puffs})^{*}$ & 4 & 0.3 \\
& $180 \mathrm{~s}(3 \mathrm{puffs})^{*}$ & 7 & 0.4 \\
& $106 \mathrm{~s}$ & 13 & 0.8 \\
& $67 \mathrm{~s}$ & 17 & 1.2 \\
& $44 \mathrm{~s}$ & 24 & 1.6 \\
& $28 \mathrm{~s}$ & 30 & 2.0 \\
\hline
\end{tabular}

\# Excluded from the calculation of the regression equation shown in Figure 4

* Removed from the smoking machine after the designated number of puffs

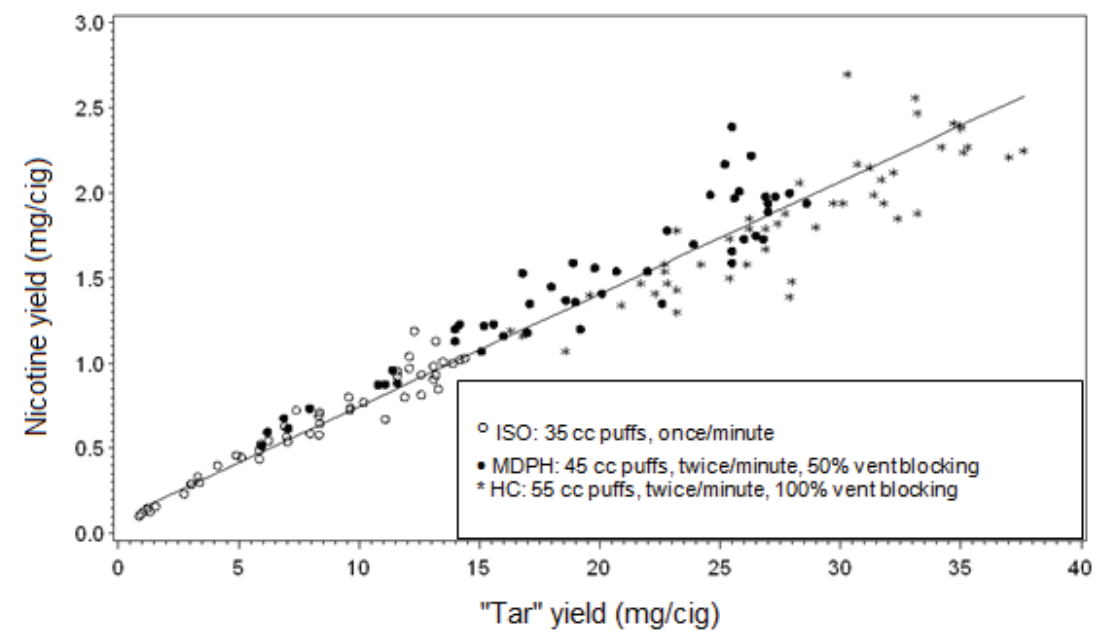

Figure 3. Data from Counts et al. (7). Reference line is equation [1]. The regression fit to the data is $y=0.091+0.066 \mathrm{x}, R^{2}=0.968$. The regression fit is not shown on the graph because it is difficult to distinguish from equation [1]. 


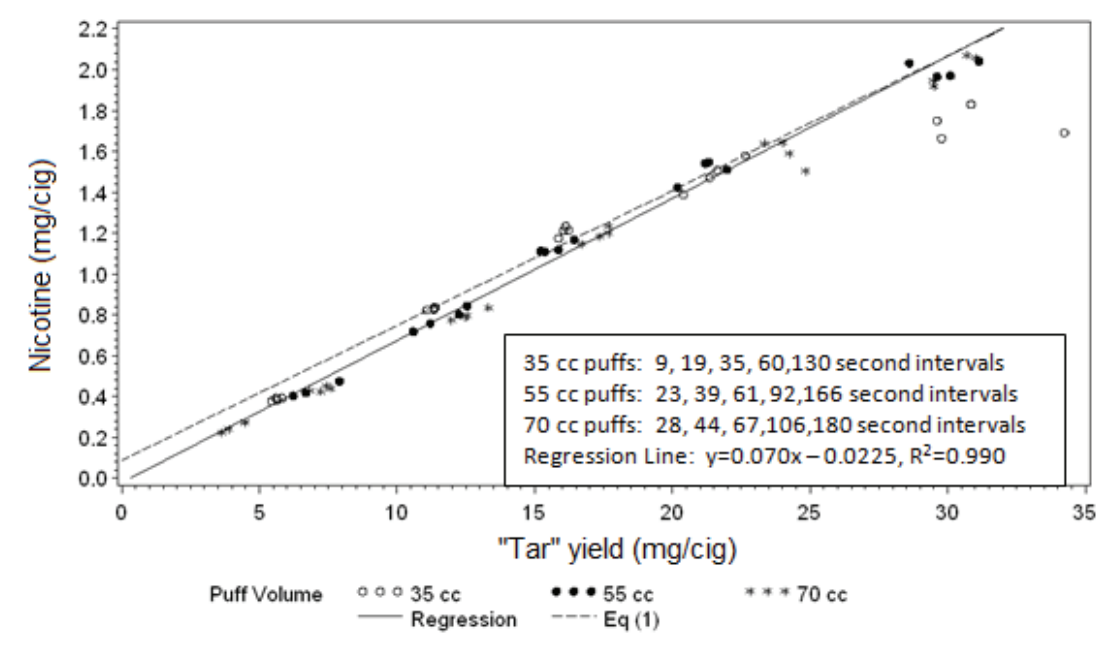

Figure 4. U.S. commercial cigarette machine-smoked with a 2-s puff interval at $35 \mathrm{cc}, 55 \mathrm{cc}$, or $70 \mathrm{cc}$ puff volume and at various interpuff intervals. The regression line excludes data using $35 \mathrm{cc}$ puff volume at the shortest puff interval and is graphed with a solid line. The dashed line is equation [1]. Data source is MORTON et al. (48). The excluded points are the four points drawn with open circles near $30 \mathrm{mg} / \mathrm{cigarette} \mathrm{"tar"} \mathrm{yield.}$

Figure 4 shows the nicotine $v s$. "tar" relationship for the data values resulting from the 16 different sets of puffing parameters. With respect to nicotine yield, the four replicates at the highest "tar" yield condition using 35 cc puffs are somewhat below the other data points with similar "tar" yields and are not included in the calculation of the regression equation. Equation [1] is also plotted for reference (the dashed line in the graph).

The regression equation in Figure 4 is similar to equation [1], but also shows some interesting differences.

1 . The intercept in the regression is not statistically significantly different from zero;

2. The nicotine yields associated with the data points under $10 \mathrm{mg}$ "tar" yield are below equation [1].

We postulate that the highest "tar" yield points using $35 \mathrm{cc}$ puffs and the lowest "tar" yield points are below equation [1] because of the pattern of nicotine deposition after a puff. In GREEN et al. (50), it is shown that following a puff the area immediately behind the firecone is partially depleted of nicotine, the region from 4 to $8 \mathrm{~mm}$ behind the firecone has a somewhat elevated nicotine concentration, presumably because of nicotine condensing onto the tobacco behind the firecone, and the concentration is gradually lower further down the rod.

For very short puff intervals, it is likely that there is not adequate time for the cigarette to smolder through the region of depleted nicotine prior to the next puff. This is likely to be the case for the very short interpuff interval associated with the highest yield data values with $35 \mathrm{cc}$ puffs. Under static burn conditions, a cigarette smolders approximately $5 \mathrm{~mm}$ per minute (PM USA unpublished results; similar results are given in 55). Following a puff, a cigarette resumes visible smoldering within about 15 to $20 \mathrm{~s}(56,57)$. So, for very long puff intervals the cigarette is likely to smolder beyond the region of maximum nicotine concentration prior to the next puff. This was likely to be the case for each of the data points with "tar" yield below $10 \mathrm{mg}$ and possibly for some of the 55 and $70 \mathrm{cc}$ puff volume points above $10 \mathrm{mg}$ "tar" yield. If the concentra- tion of nicotine in the vicinity of the puff is less, it would be expected that the nicotine yield would be somewhat lower at the same "tar" yield, consistent with the pattern seen in Figure 4.

\subsection{Refinements to the linear relationship between $C F$ nicotine and "tar" yields}

As noted above, most linear regressions of nicotine and "tar" yields result in a positive intercept. Equation [1] and similar regression equations are not consistent with the low CF or ISO "tar" yield data, since the low machine-yield cigarettes consistently have nicotine yields below the regression line. Since the tobacco blends used in very low yield products often have somewhat higher nicotine concentration, the low yield points would be expected to be above, not below the regression line, if the relationship were truly linear. Additionally the non-zero intercept in most of these equations implies, implausibly, nicotine yield approaching a positive value as the "tar" yield approaches zero.

Due to the low yield products falling below the regression line, the magnitude of the intercept varies depending on the manner in which the line is estimated and, in particular, on the relative weight given to the data points at very low "tar" yield. Equation [1] is estimated using 1/"tar" weighted regression which weights the low yield products more heavily than the higher yield products and, correspondingly, results in a smaller intercept. An unweighted regression using the same data gives an intercept of 0.15 , almost twice that seen in equation [1].

In a recent manuscript ST. CHARLES et al. (42) argued for a linear relationship with a positive intercept as being the correct model, not just a convenient and simple approximation. If one fits a linear equation using the data given for the eight "high alkaloid" products in Table 1 of ST. CHARLES et al. (42), an intercept of 0.051 results and the regression has a root mean squared error of 0.024 . Though the linear fit to these data from ST. CHARLES et al. (42) has 
a very high $\mathrm{R}^{2}$, a power law fit, going through zero, as described below, is better still with a root mean square error of 0.011 , less than half that of the linear fit.

ST. CHARLES et al. (42) rationalized the seemingly implausible positive intercept with the observation that sometimes negative "tar" yields can be observed. When an inherently positive quantity is calculated by subtraction, it is possible to obtain negative calculated values. Total particulate matter (TPM) is intended to be the particulate phase yield of a cigarette and its calculation can be thought of as the per cigarette weight difference in the Cambridge filter pad before and after smoking. For very low yield products, water already present on the Cambridge filter pad prior to smoking can be driven off during smoking, resulting in a negative calculated TPM, and ultimately to a negative calculated "tar". Difficulties in the measurement of very low yields can also result from analytical variability in the determination of water on the Cambridge pad and variation in the determination of weight (58). Though a negative TPM or "tar" yield is not physically meaningful, we understand that it can happen analytically when a value is calculated by subtraction. More generally, we recognize the difficulties inherent in measuring very low smoke yields. Nonetheless, as we show below, a non-linear equation with a zero intercept better fits the available data in addition to being more physically plausible.

Some researchers have proposed non-linear relationships between MS smoke nicotine and "tar" yields for improved fit of the data. ROEMER et al. (59) used a power function to fit nicotine yield as a function of "tar" yield under ISO conditions, and the same functional form was utilized in COUNTS et al. (7). Fitting a power function to the data used to generate equation [1] gives

Nicotine $=0.121 \times(\text { "tar" })^{0.811}$

The weighted $\mathrm{R}^{2}$ for this model is 0.966 . As found here, the value of the exponent is generally estimated to be in the vicinity of 0.8 , consistent with the observation that the relationship between "tar" and nicotine is concave down. After excluding the low alkaloid "outlier" points from the market samples shown earlier, Figure 5 shows the market sample data points together with equations [1] and [2].

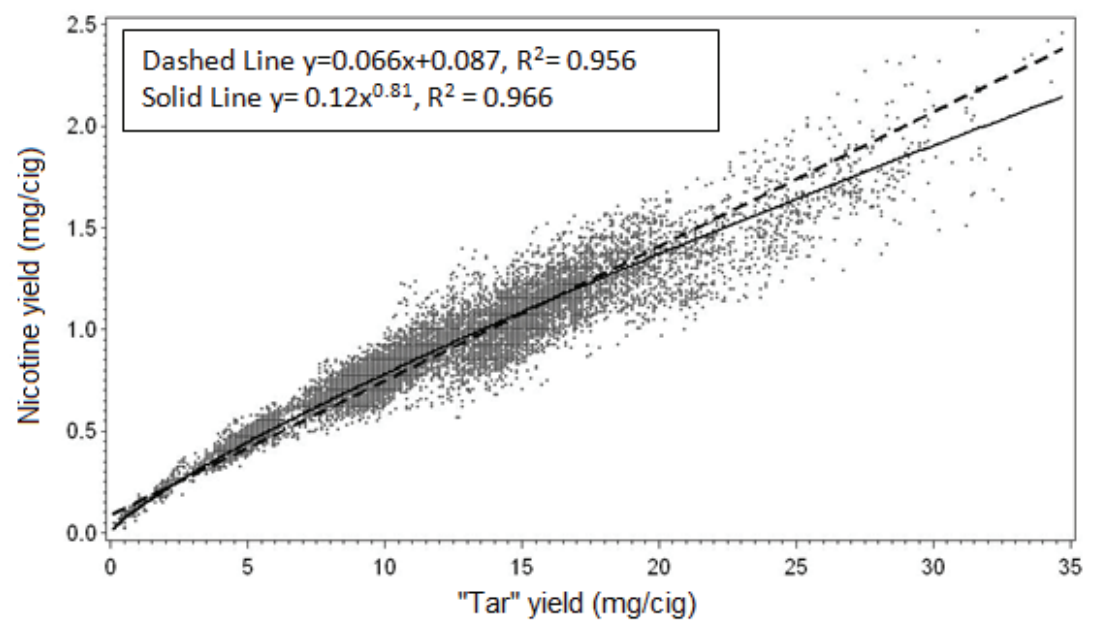

Figure 5. Market samples from 1967 to 2008 excluding 215 "outlier" points. Equations [1] and [2] are shown for comparison. Both fits were calculated excluding 215 "outlier" points.

Table 3. $\mathbf{R}^{2}$ values for linear and power function models used to predict CF nicotine using data for U.S. commercial cigarettes. The regressions are weighted using "tar"-1 as the weighting factor.

\begin{tabular}{|c|c|c|c|c|}
\hline \multirow{2}{*}{ Independent variable } & \multicolumn{4}{|c|}{$\mathrm{R}^{2}$ for linear fit } \\
\hline & 1981 & 1992 & 1995 & 1996 \\
\hline CF "tar" & 0.973 & 0.964 & 0.955 & 0.965 \\
\hline CF "tar" $\times$ concentration of nicotine in tobacco & 0.989 & 0.964 & 0.973 & 0.979 \\
\hline \multirow[t]{2}{*}{ CF "tar" $\times$ weight of nicotine in tobacco } & 0.972 & 0.932 & 0.948 & 0.958 \\
\hline & \multicolumn{4}{|c|}{$R^{2}$ for power function fit } \\
\hline CF "tar" & 0.991 & 0.984 & 0.979 & 0.985 \\
\hline CF "tar" $\times$ concentration of nicotine in tobacco & 0.997 & 0.984 & 0.993 & 0.995 \\
\hline CF "tar" $\times$ weight of nicotine in tobacco & 0.993 & 0.975 & 0.988 & 0.992 \\
\hline
\end{tabular}


We see that the power law curve better captures the low yield behavior and overall has a better correlation. It is also consistent with the non-constancy in the "tar"/nicotine ratio discussed in Section 3.4. However, being simply an empirical fit to the data, it should not be extrapolated outside the range used to estimate the equation.

Though the correlations using "tar" yield alone as the predictor variable are generally quite good, there is still product-to-product variation around the regression lines, as can be seen in Figure 1 and other products that appear to not fit the relationship. Not surprisingly, it has been found that information related to the nicotine content of the cigarette filler often helps to explain portions of that variation $(31,42)$. However, it is somewhat uncommon to have filler nicotine information in conjunction with "tar" and nicotine yields. So we merged historical data for four years combining CF "tar" and nicotine yield data with tobacco filler nicotine data available from internal testing conducted at PM USA. The data sets represent a broad picture of the 1981, 1992, 1995 and 1996 U.S. commercial cigarettes.

Both MORTON and LAFFOON (31) and ST. CHARLES et al. (42) used the concentration of nicotine in the cigarette filler in conjunction with the "tar" yield of the cigarette to help explain the nicotine yield. CounTs et al. (7) used a similar model to explain nitrosamine yields. However COUNTS et al. (6) used the total amount of the nitrosamine in the cigarette to aid in the estimation of the corresponding nitrosamine in the smoke. The authors have found many experienced tobacco scientists who believe that the total amount of the constituent in the cigarette would better explain the corresponding smoke yield than would the concentration. For those reasons we explicitly compare the two ways of expressing the cigarette nicotine content, concentration (e.g., mg of nicotine per gram dry weight of tobacco) and amount (e.g., mg per cigarette).

Table 3 reports the proportion of the variance of CF nicotine yield explained by six alternative predictors. Three are linear functions of CF "tar", of CF "tar" times the concentration of nicotine in the cigarette tobacco, and of CF "tar" times the weight of nicotine in the cigarette tobacco. Three are power functions using the same $\mathrm{x}$-variables. Of course, analogous equations can be employed for machine-smoking methods other than the CF method. For reference, we include parameterized versions of equations [1] and [2] as well.

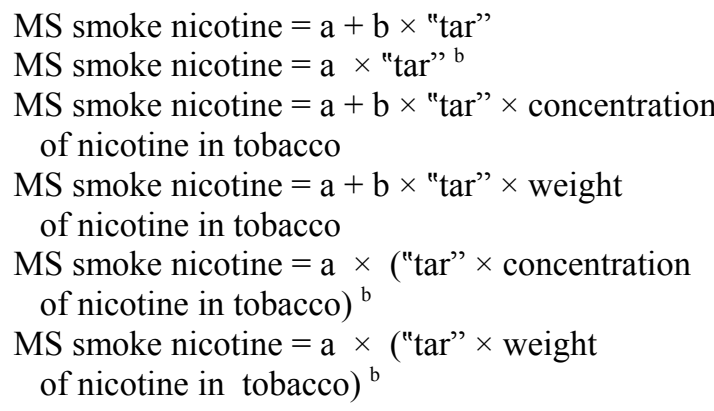

All the regressions shown in Table 3 use a regression weighting factor of "tar"-1. In all the linear functions "a" and " $b$ " represent the intercept and slope, respectively. In the power functions equations [2], [5] and [6], there is no intercept, "a" is a scaling factor, "b" is the exponent, and the parameters are fitted using non-linear regression, employing SAS/STAT ${ }^{\mathbb{B}}$ Version 9.1 (60).

Greater than $95 \%$ of the variance in the CF nicotine and "tar" data is explained with a linear fit considering "tar" alone. Even so, in each case, the fit improves substantially when non-linearity is taken into account with a power function. It is informative to examine the unexplained variance, $1-\mathrm{R}^{2}$, which is often reduced by a factor of more than two. The unexplained variance is related to the prediction error associated with the regression equation. For example, using the 1981 data set, $1-\mathrm{R}^{2}$ changes from $1-0.973=0.027$ using a linear fit to $1-0.991=0.009$ using a power function fit. Using the variable "tar" $\times$ nicotine concentration in tobacco" generally improves the fit further (though makes no difference for the 1992 data) and always does better than using "tar" $\times$ weight of nicotine in tobacco", which often performs worse than "tar" alone.

Nicotine smoke yield under MDPH machine-smoking conditions and tobacco filler nicotine content are also measured for selected brand families for reporting to the Commonwealth of Massachusetts and the State of Texas. Nicotine machine-smoke yield has been reported since 1997 using the MDPH machine-smoking protocol. Moisture of the filler was also internally available for the years 1998 2010 and was approximated for 1997 assuming 11.75\% tobacco moisture, the average in 1998. That allowed the calculation of the dry weight nicotine concentration. In Table 4, the regression models for smoke nicotine for the PM USA Marlboro and Basic brands reported to Massachusetts and Texas are summarized using "tar" alone as an explanatory variable, using "tar" times tobacco dry weight nicotine concentration, and "tar" times nicotine amount. The regressions were calculated each year and overall. In each year except 1997 the regressions are improved by including tobacco nicotine concentration over using "tar" yield alone. The differences in the regressions from yearto-year are statistically significant $(\mathrm{p}<0.0001)$, even restricting the products in the regression to those common to all years, and likely reflect a combination of temporal variation in the analytical methods and year-to-year variation in tobaccos and other materials. However, the curvature to the relationship of "tar" and nicotine is less important in the range of "tar" yields produced by smoking under MDPH conditions and the curvature is not statistically significant in any of the years 1997-2010.

Nicotine concentration is likely to be more helpful beyond using "tar" yield alone the greater the product-to-product filler nicotine differences and the more accurately those differences are measured. Indeed if the differences in the filler nicotine concentrations from one product to another are minimal, the measurement error involved in determining the nicotine concentrations can make the predictions incorporating the measured nicotine concentration worse than using "tar" yield alone. This may be the explanation for why "tar" alone was a better predictor in 1997 than a model including tobacco filler nicotine. In 1997 PM USA testing was only required of products from the Marlboro brand family which had relatively similar tobacco blends. One of the reasons that the relationship between "tar" and nicotine yields is so good is because most of the cigarette products in the U.S. marketplace are similarly constructed 
Table 4. Regression of MDPH machine-smoked nicotine yields against "tar" yield, against "tar" yield times tobacco nicotine concentration, and "tar" yield times nicotine amount for PM USA Marlboro and Basic cigarette products reported to MDPH or TXDSHS. In 1997 nicotine reporting was required for the Marlboro brand family, but not the Basic brand family. Nicotine concentration is measured in dry weight percent and nicotine amount is measured in milligrams.

\begin{tabular}{|c|c|c|c|c|c|c|c|c|c|}
\hline \multirow{2}{*}{ Year } & \multicolumn{3}{|c|}{ "Tar" alone } & \multicolumn{3}{|c|}{ "Tar"*nicotine concentration } & \multicolumn{3}{|c|}{ "Tar"*nicotine amount } \\
\hline & Int. & Slope & $\mathrm{R}^{2}$ & Int. & Slope & $\mathrm{R}^{2}$ & Int. & Slope & $\mathrm{R}^{2}$ \\
\hline 1997 & 0.124 & 0.065 & $98.3 \%$ & 0.190 & 0.030 & $87.9 \%$ & 0.611 & 0.0035 & $89.5 \%$ \\
\hline 1998 & 0.146 & 0.061 & $91.7 \%$ & 0.143 & 0.032 & $96.9 \%$ & 0.582 & 0.0034 & $93.7 \%$ \\
\hline 1999 & 0.169 & 0.062 & $95.0 \%$ & 0.151 & 0.033 & $96.9 \%$ & 0.557 & 0.0036 & $92.6 \%$ \\
\hline 2000 & 0.077 & 0.066 & $91.8 \%$ & 0.095 & 0.032 & $98.5 \%$ & 0.548 & 0.0033 & $94.4 \%$ \\
\hline 2001 & 0.127 & 0.065 & $89.8 \%$ & 0.129 & 0.031 & $95.6 \%$ & 0.422 & 0.0038 & $95.7 \%$ \\
\hline 2002 & 0.150 & 0.068 & $92.8 \%$ & 0.127 & 0.032 & $96.9 \%$ & 0.470 & 0.0038 & $94.2 \%$ \\
\hline 2003 & 0.156 & 0.068 & $94.0 \%$ & 0.137 & 0.033 & $97.5 \%$ & 0.504 & 0.0040 & $93.7 \%$ \\
\hline 2004 & 0.133 & 0.067 & $96.1 \%$ & 0.137 & 0.033 & $97.7 \%$ & 0.457 & 0.0042 & $95.1 \%$ \\
\hline 2005 & 0.114 & 0.065 & $92.0 \%$ & 0.131 & 0.033 & $95.2 \%$ & 0.437 & 0.0042 & $93.1 \%$ \\
\hline 2006 & 0.114 & 0.063 & $88.7 \%$ & 0.136 & 0.032 & $95.1 \%$ & 0.425 & 0.0041 & $90.5 \%$ \\
\hline 2007 & 0.093 & 0.063 & $82.8 \%$ & 0.119 & 0.031 & $94.1 \%$ & 0.409 & 0.0041 & $90.8 \%$ \\
\hline 2008 & 0.127 & 0.062 & $84.6 \%$ & 0.091 & 0.031 & $95.8 \%$ & 0.475 & 0.0037 & $89.6 \%$ \\
\hline 2009 & 0.137 & 0.062 & $85.1 \%$ & 0.080 & 0.032 & $94.6 \%$ & 0.480 & 0.0039 & $90.6 \%$ \\
\hline 2010 & 0.060 & 0.067 & $79.6 \%$ & 0.134 & 0.033 & $96.1 \%$ & 0.420 & 0.0044 & $92.9 \%$ \\
\hline Overall & 0.141 & 0.064 & $86.2 \%$ & 0.144 & 0.032 & $93.9 \%$ & 0.513 & 0.0038 & $89.4 \%$ \\
\hline
\end{tabular}

"American Blend" cigarettes. If marketplace blends were more different from one another, the relationship between "tar" and nicotine would be much looser.

As noted above, some researchers have used weight of the associated tobacco constituent to aid in the prediction or explanation of the corresponding smoke constituent. More commonly the concentration of the constituent has been used. The results in Tables 3 and 4 indicate that concentration is preferable to weight. The next example illustrates that, though preferable, nicotine concentration even in conjunction with "tar" yield is not complete.
It is commonplace within a brand family to have product pairs of differing length, such as a "king size" and a "100's," with the same tobacco blend and similar "tar" yields. In this case, there is typically more cigarette filler in the longer cigarette, and, therefore, more total nicotine. If the products use the same filler, the nicotine concentrations will be the same, and, if nicotine concentration together with "tar" yield were the complete explanation of the nicotine yield, then one would expect the nicotine yields to be the same if the "tar" yields are the same.

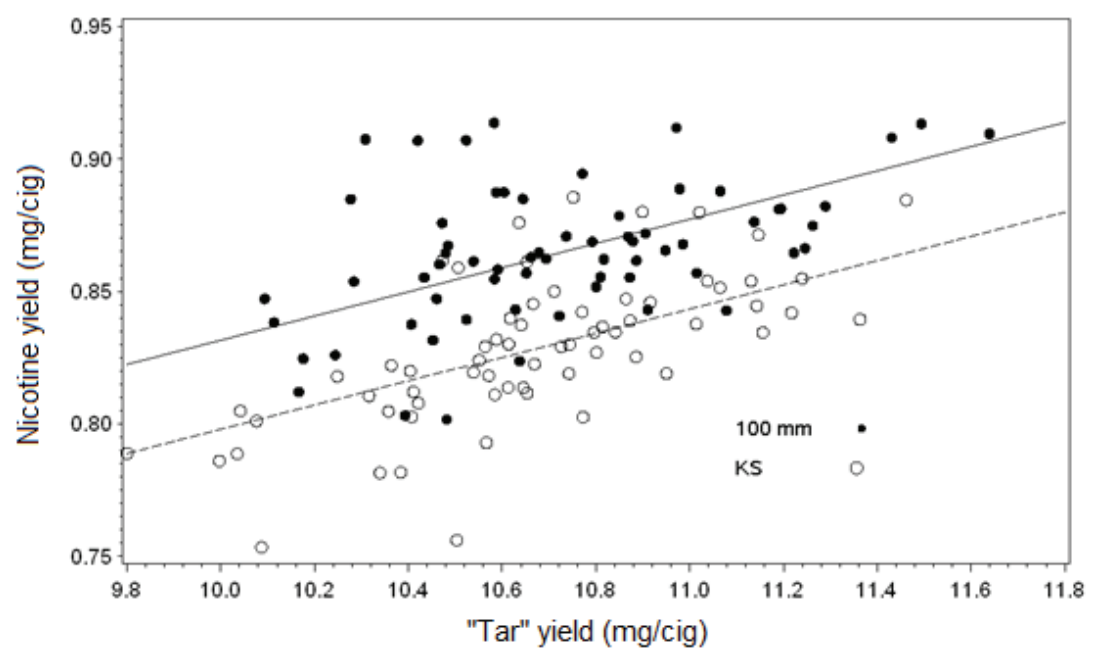

Figure 6. A comparison between the CF nicotine yields of a King Size and 100's cigarettes. The two products have the same tobacco blend and similar "tar" yields. The regression lines are used to adjust for the small "tar" yield differences using an analysis of covariance. The $4 \%$ difference in nicotine yield is much smaller than the $19 \%$ weight difference, but is statistically significant $(p<0.0001)$. 
To illustrate, two years of PM USA internal production monitoring data are examined for a commercial king size and $100 \mathrm{~mm}$ cigarette. The two products were both smoked for CF "tar" and nicotine 65 times over the two year time period. The tobacco blend and thus the nicotine concentrations were the same for the two products. By target weight, the $100 \mathrm{~mm}$ cigarette had about $19 \%$ more tobacco and therefore about $19 \%$ more total nicotine in the tobacco. Over the two year period there would be variation in the tobaccos and other materials and long-term analytical variation in the determination of "tar" and nicotine yields. However, the two products were sampled and tested at the same time points, so tobacco and analytical method variation are balanced between the two products. When looking for subtle differences, it is very important that product differences not be confounded with temporal or other effects and maintaining balance in those factors achieves that goal.

The data are graphed in Figure 6, and, when adjusted for the slight CF "tar" yield differences using "tar" as a covariate in the comparison, the $\mathrm{CF}$ nicotine yields were $0.86 \mathrm{mg} / \mathrm{cig}$ and $0.83 \mathrm{mg} / \mathrm{cig}$ for the $100 \mathrm{~mm}$ and the king size cigarette, respectively. The nicotine yield difference is much less than the $19 \%$ weight difference, but is still statistically significantly different from zero $(p<0.0001)$. This is consistent with the observation above that concentration of nicotine in the cigarette blend is more effective than amount of nicotine in the cigarette in explaining smoke nicotine yields. However it is also a reminder that equations such as [3] or [5] are just convenient empirical approximations and not complete explanations. Though not shown here, we have examined the phenomenon over several product pairs and several years and the phenomenon of longer cigarettes resulting in higher nicotine yields (holding "tar" yield and tobacco blend constant) has been found consistently.

\section{THE "TAR"-TO-NICOTINE RATIO}

The ratio of CF "tar" to nicotine is graphed in Figure 7 for the 2008 U.S. commercial cigarettes and the ratio is seen to increase with "tar" yield. The relationship shown in Figure 7 is typical of that found for the largely American blend U.S. commercial cigarette market in other years. This phenomenon has long been known and its potential impact on smoker exposure was discussed in GORI and LYNCH (61).

The non-constant "tar" to nicotine ratio is consistent with any number of "tar" and nicotine relationships. For example, using a relationship similar to that shown in equation [2] gives

"Tar"/nicotine = "tar"/(0.12 × "tar" $\left.{ }^{\circ} 0.81\right)=$ "tar" $0.19 / 0.12$

which is an increasing function of "tar". A similar power law relationship was found when the nicotine concentration of the tobacco filler was incorporated.

The reason both for the non-linearity of the "tar" and nicotine relationship and the non-constancy of the "tar" to nicotine ratio may relate, among other potential factors, to nicotine's eluting more readily from the cigarette filter or the tobacco itself than most other particulate phase compounds as shown in CURRAN and KIEFER (62) and discussed in NORMAN (63). This may have a proportionately greater effect with lower yield or longer cigarettes.

Another possible explanation could be the effect of ventilation. NORMAN (64) showed that ventilation reduces cigarette nicotine yield proportionately less than "tar" yield. Low yield cigarettes typically have high ventilation. Similarly for a $100 \mathrm{~mm}$ cigarette to have a comparable "tar" yield to that of a king size cigarette, it typically has a higher ventilation. In the example shown in Figure 6, the ventilation of the $100 \mathrm{~mm}$ cigarette was $28 \%$ and the king size ventilation was $23 \%$.

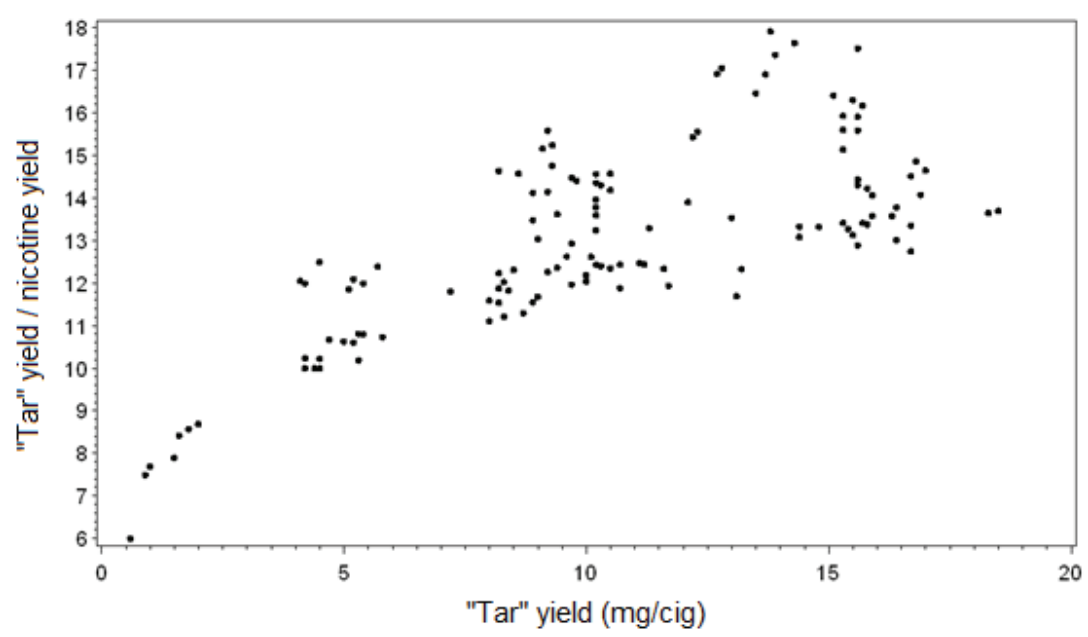

Figure 7. Relationship between the ratio of "tar" to nicotine versus "tar" for 2008 U.S. commercial cigarettes from Market Sample \#51 using the CF machine-smoking method. The Eclipse cigarettes were excluded from the graph as outliers. 


\section{SUMMARY AND CONCLUSIONS}

Machine smoking methods are incorporated in regulatory requirements in the U.S., Canada, and around the world, and have served for decades as useful tools to investigate the mechanisms of tobacco smoke formation and to evaluate the effect of ingredients and cigarette design on smoke formation and MS smoke yields.

For multiple data sets comprising commercial cigarettes from 1967-2010 and CF, ISO, MDPH, and HC smoking regimens, we find that the data are typically well fit by the linear relationship given by equation [1]. However, we did find a number of refinements to that model and circumstances under which it may not apply:

- We found that very low yield products tend to have ISO or $\mathrm{CF}$ yields below the regression line. A power law fit to the data is a simple approach accounting for this nonlinearity.

- Denicotinized or otherwise reduced nicotine products fall below the regression line.

- Very short or very long intervals between puffs may give results below equation [1].

- Utilizing the nicotine concentration in conjunction with the "tar" yield improves the prediction of the corresponding nicotine yields. We did illustrate, however, that nicotine concentration alone, even in conjunction with the "tar" yield, does not completely account for the corresponding nicotine yield. For example, with the same tobacco blend and the same "tar" yield, a $100 \mathrm{~mm}$ cigarette showed a roughly $4 \%$ higher nicotine yield than its king size counterpart.

- The ratio of "tar" to nicotine yield is an increasing function of "tar" yield. The power law equation is consistent with the observed non-constant "tar" to nicotine ratio.

\section{ACKNOWLEDGMENTS}

The authors thank Dr. Allen Kassman for helpful discussions on these topics. The work by Dr. Jeffrey I. Seeman was performed as a consultant to Philip Morris USA.

\section{REFERENCES}

1. Baker, R.R. and L.J. Bishop: The Pyrolysis of Tobacco Ingredients; J. Anal. Appl. Pyrolysis 71 (2004) 223-311.

2. Baker, R.R., E.D. Massey, and G. Smith: An Overview of the Effects of Tobacco Ingredients on Smoke Chemistry and Toxicity; Food Chem. Toxicol. 42S (2004) S53-S83.

3. Baker, R.R., J.R. Pereira da Silva, and G. Smith: The Effect of Tobacco Ingredients on Smoke Chemistry. Part I: Flavorings and Additives; Food Chem. Toxicol. 42S (2004) S3-S37.

4. Carmines, E.L.: Evaluation of the Potential Effects of Ingredients Added to Cigarettes. Part 1: Cigarette Design, Testing Approach, and Review of Results; Food Chem. Toxicol. 40 (2002) 77-91.

5. Chepiga, T.A., M.J. Morton, P.A. Murphy, J.T. Avalos, B.R. Bombick, D.J. Doolittle, M.F.
Borgerding, and J.E. Swauger: A Comparison of the Mainstream Smoke Chemistry and Mutagenicity of a Representative Sample for the U.S. Cigarette Market with two Kentucky Reference Cigarettes (K1R4F and K1R5F); Food Chem. Toxicol. 38 (2000) 949-962.

6. Counts, M.E., F.S. Hsu, S.W. Laffoon, R.W. Dwyer, and R.H. Cox: Mainstream Smoke Constituent Yields and Predicting Relationships From a Worldwide Market Sample of Cigarette Brands: ISO Smoking Conditions; Regul. Toxicol. Pharmacol. 39 (2004) 111-134.

7. Counts, M.E., M.J. Morton, S.W. Laffoon, R.H. Cox, and P.J. Lipowicz: Smoke Composition and Predicting Relationships for International Commercial Cigarettes Smoked with Three Machine-Smoking Conditions; Regul. Toxicol. Pharmacol. 41 (2005) 185-227.

8. Counts, M.E., F.S. Hsu, and F.J. Tewes: Development of a Commercial Cigarette "Market Map" Comparison Methodology for Evaluating New or Non-Conventional Cigarettes; Regul. Toxicol. Pharmacol. 46 (2006) 225-242.

9. Gaworski, C.L., M.J. Oldham, K.A. Wagner, C.R.E. Coggins, and G.J. Patskan: An Evaluation of the Toxicity of 95 Ingredients Added Individually to Experimental Cigarettes: Approach and Methods; Inhal. Toxicol. 23 (S1) (2011) 1-12.

10. Gaworski, C.L., K.A. Wagner, M.J. Morton, and M.J. Oldham: Insights From a Multi-Year Program Designed to Test the Impact of Ingredients on Mainstream Cigarette Smoke Toxicity; Inhal. Toxicol. 23 (S1) (2011) 1-12.

11. Green, C.R., J.N. Schumacher, R.A. Lloyd Jr, and A. Rodgman: Comparisons of the Composition of Tobacco Smoke and the Smokes from Various Tobacco Substitutes; Beitr. Tabakforsch. Int. 22 (2007) 258-289.

12. Harris, J.E.: Incomplete Compensation Does Not Imply Reduced Harm: Yields of 40 Smoke Toxicants per Milligram Nicotine in Regular Filter Versus LowTar Cigarettes in the 1999 Massachusetts Benchmark Study; Nicotine Tob. Res. 6 (2004) 797-807.

13. Hoffmann, D. and I. Hoffmann: The Changing Cigarette: Chemical Studies and Bioassays; in: Risks Associated with Smoking Cigarettes with Low MachineMeasured Yields of Tar and Nicotine, Smoking and Tobacco Control Monograph No. 13., U.S. Department of Health and Human Services, National Institutes of Health, National Cancer Institute, Bethesda, MD, USA, pp. 159-191, 2001.

14. Rodgman, A. and T.A. Perfetti: The Composition of Tobacco Smoke: A Chronology of the Studies of Four Polycyclic Aromatic Hydrocarbons; Beitr. Tabakforsch. Int. 22 (2006) 208-254.

15. Roemer, E., F.J. Tewes, T.J. Meisgen, D.J. Veltel, and E.L. Carmines: Evaluation of the Potential Effects of Ingredients Added to Cigarettes. Part 3: In Vitro Genotoxicity and Cytotoxicity; Food Chem. Toxicol. 40 (2002) 105-111.

16. Rustemeier, K., R. Stabbert, H.-J. Haussmann, E. Roemer, and E.L. Carmines: Evaluation of the Potential Effects of Ingredients Added to Cigarettes. Part 2: Chemical Composition of Mainstream Smoke; Food Chem. Toxicol. 40 (2002) 93-104. 
17. Stavanja, M.S., P.H. Ayres, D.R. Meckley, B.R. Bombick, D.H. Pence, M.F. Borgerding, M.J. Morton, A.T. Mosberg, and J.E. Swauger: Toxicological Evaluation of Honey as an Ingredient Added to Cigarette Tobacco; J Toxicol Environ Health Part A. 66 (2003) 1453-1474.

18. Stavanja, M.S., P.H. Ayres, D.R. Meckley, E.R. Bombick, M.F. Borgerding, M.J. Morton, C.D. Garner, D.H. Pence, and J.E. Swauger: Safety Assessment of High Fructose Corn Syrup (HFCS) as an Ingredient Added to Cigarette Tobacco; Exp. Toxicol. Pathol. 57 (2006) 267-281.

19. Stephens, W.E.: Dependence of Tar, Nicotine and Carbon Monoxide Yields on Physical Parameters: Implications for Exposure, Emissions Control and Monitoring; Tob. Control 16 (2007) 170-176.

20. Theophilus, E.H., B.R. Bombick, D.R. Meckley, M.A. Higuchi, M.F. Borgerding, M.J. Morton, A.T. Mosberg, and J.E. Swauger: Toxicological Evaluation of Propane Expanded Tobacco; Food Chem. Toxicol. 41 (2003) 1771-1780.

21. Theophilus, E.H., D.B. Poindexter, D.R. Meckley, B.R. Bombick, M.F. Borgerding, M.A. Higuchi, P.H. Ayres, M.J. Morton, A.T. Mosberg, and J.E. Swauger: Toxicological Evaluation of Dry Ice Expanded Tobacco; Toxicol. Letters. 145 (2003) 107-119.

22. Vanscheeuwijck, P.M., A. Teredesai, P.M. Terpstra, J. Verbeeck, P. Kuhl, B. Gerstenberg, S. Gebel, and E.L. Carmines: Evaluation of the Potential Effects of Ingredients Added to Cigarettes. Part 4: Subchronic Inhalation Toxicity; Food Chem. Toxicol. 40 (2002) 113-131.

23. Baker, R.R.: The Development and Significance of Standards for Smoking-Machine Methodology; Beitr. Tabakforsch. Int. 20 (2002) 23-41.

24. FTC 1967 Press Release, August 1, 1967; Available at http://www.pmi.com/eng/tobacco_regulation/ regulating_tobacco/regulation_of_tobacco_smoke/ documents/1967_ftc_press_release_ftc\% $\%$ 20to $\% 20$ begin $\% 20$ cigarette\%20testing.pdf (accessed December 2013)

25. National Cancer Institute: The FTC Cigarette Test Method for Determining Tar, Nicotine, and Carbon Monoxide Yields of U.S. Cigarettes; Smoking and Tobacco Control Monograph No. 7. Department of Health and Human Services, National Institutes of Health, National Cancer Institute, Bethesda, MD, USA (1996) NIH Pub. No. 96-4028 (Chapters 1, 2, 9, 11).

26. National Cancer Institute: Risks Associated with Smoking Cigarettes with Low Machine-Measured Yields of Tar and Nicotine, Smoking and Tobacco Control Monograph No. 13. Department of Health and Human Services, National Institutes of Health, National Cancer Institute, Bethesda, MD, USA (2001) NIH Pub. No. 02-5074 (Chapters 3, 6, 7).

27. Rodgman, A.: FTC 'Tar' and Nicotine in Mainstream Smoke: A retrospective; Rec. Adv. Tob. Sci. 23 (1997) 5-74.

28. Connolly, G.N., H. R. Alpert, G.F. Wayne, and H. Koh: Trends in Nicotine Yield in Smoke and its Rela- tionship with Design Characteristics Among Popular U.S. Cigarette Brands 1997-2005; Tob. Control (2007) 16(5):e5.

29. Borgerding, M.F., J.A. Bodnar, D.E. Wingate, C.R. Taylor, J.R. Reid, M.A. Sudholz, K.F. Podraza, F.S. Hsu, and J.F. Whidby: The 1999 Massachusetts Benchmark Study; Massachusetts Department of Public Health under the Massachusetts public records law, 2000. Available at http://legacy.library.ucsf.edu/ documentStore/y/e/k/yek21c00/Syek21c00.pdf (accessed December 2013).

30. Gregg, E., C. Hill, M. Hollywood, M. Kearney, K. McAdam, D. McLaughlin, S. Purkis, and M. Williams: The UK Smoke Constituents Testing Study. Summary of Results and Comparison With Other Studies; Beitr. Tabakforsch. Int. 21 (2004) 117-138.

31. Morton, M.J. and S.W. Laffoon: Cigarette Smoke Chemistry Market Maps under Massachusetts Department of Public Health Smoking Conditions; Regul. Toxicol. Pharm. 51 (2008) 1-30.

32. Swauger, J.E., T.J. Steichen, P.A. Murphy, and S. Kinsler: An Analysis of the Mainstream Smoke Chemistry of Samples of the U.S. Cigarette Market Acquired Between 1995 and 2000; Regul. Toxicol. Pharm. 35 (2002) 142-156.

33. Laugesen, M. and J. Fowles: Marlboro Ultrasmooth: A Potentially Reduced Exposure Cigarette?; Tob. Control 15 (2006) 430-435.

34. van Amsterdam, J.G.C., T.M. Brunt, A.P.J. Verlaan, R.F.M.J. Cleven, A. Opperhuizen, and W. Vleeming: The Relation Between the Quantity of Ammonium Compounds in Tobacco and the Nitrogen Monoxide (NO) Levels in the Smoke of Cigarettes Marketed in the Netherlands; Beitr. Tabakforsch. Int. 22 (2006) 196-203.

35. Watson, C., J. McCraw, G. Polzin, and D.L. Ashley: Development of a Method to Assess Cigarette Smoke Intake; Environ. Sci. Technol. 38 (2004) 248-253.

36. Hammond, D., F. Wiebel, L.T. Kozlowski, R. Borland, K.M. Cummings, R.J. O'Connor, A. McNeill, G.N. Connolly, D. Arnott, and G.T. Fong: Revising the machine smoking regime for cigarette emissions: Implications for tobacco control policy. Tob. Control 16 (2007) 8-14.

37. World Health Organization: Scientific Advisory Committee on Tobacco Product Regulation (SACTob) Recommendation on Tobacco Product Ingredients and Emissions (2004); Available at http://www.who.int/tobacco/sactob/recommendations/ en/ingredients_en.pdf (accessed August 10, 2011).

38. World Health Organization: The Scientific Basis of Tobacco Product Regulation: Report of a WHO Study Group. WHO Technical Report Series 945 (2007); Available at http://www.who.int/tobacco/global interaction/tobreg/who_tsr.pdf (accessed August 10, 2011).

39. Kozlowski, L.T., N.Y. Mehta, C.T. Sweeney, S.S. Schwartz, G.P. Vogler, M.J. Jarvis, and R.J. West: Filter Ventilation and Nicotine Content of Tobacco in Cigarettes from Canada, the United Kingdom, and the United States; Tob. Control 7 (1998) 369-375.

40. Moore, G.E., I. Bross, R. Shamberger, and F.G. Bock: 
Tar and Nicotine Retrieval from Fifty-Six Brands of Cigarettes; Cancer 20 (1967) 323-332.

41. Moore, G.E. and F.G. Bock: "Tar" and Nicotine Levels of American Cigarettes; in: National Cancer Institute Monograph 28: Toward a Less Harmful Cigarette, U.S. Department of Health, Education, and Welfare, Public Health Service, Bethesda, MD, USA (1968) pp. 89-94.

42. St. Charles, F.K., C.J. Cook, and P.M. Clayton: The Linear Relationship Between Cigarette Tar and Nicotine Yields: Regulatory Implications for Smoke Constituent Ratios; Regul. Toxicol. Pharm. 59 (2011) 143-148.

43. Federal Register, August 1, 1967. Cigarettes: Testing for Tar and Nicotine Content; Vol. 32, No. 147, p. 11178.

44. International Organization for Standardization (ISO): International Standard ISO 4387; Third Ed., Cigarettes - Determination of Total and Nicotine-Free Dry Particulate Matter Using a Routine Analytical Smoking Machine. ISO, Geneva, Switzerland, 2000.

45. International Organization for Standardization (ISO): International Standard ISO 10315 Second Ed. and Corrigendum I, 2000 Cigarettes - Determination of Nicotine in Smoke Condensates - Gas Chromatographic Method. ISO, Geneva, Switzerland, 2000.

46. Massachusetts General Laws: Chapter 94, Sect. 307B, 105 Code of Massachusetts Regulations 660.000 et seq., 1997.

47. Canada, 2000. Canada Government Tobacco Act: Tobacco Reporting Regulations, SOR/2000-273. Registration June 26, 2000. Schedule 2: Official Methods for Collection of Emission Data on Mainstream Smoke. Methods available at: http://www.hcsc. gc.ca/ hecs-sesc/tobacco/legislation/index_testmethods main.html (accessed 2013) or through Health Canada, Tobacco Control Programme, P.L. 3506C, Ottawa, Canada, K1A 0K9.

48. Morton, M.J., D.L. Williams, H.B. Hjorth, and J.H. Smith: Machine-Smoking of Cigarette Filter Color to Estimate Tar Yield by Visual Assessment and Through the Use of a Colorimeter; Regul. Toxicol. Pharm. 56 (2010) 321-331.

49. Ehmke, H. and G. Neurath: Einfluss des Feuchtigkeitsgehaltes von Cigaretten auf die Zusammensetzung des Rauches II (The Influence of Tobacco Moisture Content on the Composition of Mainstream Smoke II); Beitr. Tabakforsch. 2 (1964) 205-208.

50. Green, C.R., F.W. Conrad, M.F. Dube, J.L. Harris, and A.L. Angel: Dry Cigarette Chemistry; RJR Internal Report (1982) Available at: http://www.legacy. library.ucsf.edu/tid/gff97c00/pdf (accessed June 28, 2009).

51. Neurath, G. and H. Horstmann: Einfluss des Feuchtigkeitsgehaltes von Cigaretten auf die $\mathrm{Zu}-$ sammensetzung des Rauches und die Glutzonentemperatur (The Influence of Tobacco Moisture Content on the Composition of Mainstream Smoke as Well as on the Temperature in the Combustion Zone); Beitr. Tabakforsch. 2 (1963) 93-100.

52. Zha, Q. and S.C. Moldoveanu: The influence of cigarette moisture to the chemistry of particulate phase smoke of a common commercial cigarette. Beitr. Tabakforsch. Int. 21 (2004) 93-100.

53. Littel, R.C., G.A. Milliken, W.W. Stroup, R.D. Wolfinger, and O. Schabenberger: SAS for Mixed Models; Second Ed. SAS Institute Inc., Cary, NC, USA, 2006.

54. Verbeke, G. and G. Molenberghs: Linear Mixed Models for Longitudinal Data; New York, SpringerVerlag, 2000.

55. Miura, K., S. Kitao, Y. Egashira, N. Nishiyama, and K. Ueyama: Propagation of Cigarette Static Burn; Beitr. Tabakforsch. Int. 19 (2001) 277-287.

56. Baker, R.R.: Temperature Variation Within a Cigarette Combustion Coal During the Smoking Cycle; High Temp. Sci. 7 (1975) 236-247.

57. Baker, R.R.: Variation of the Gas Formation Regions Within a Cigarette Combustion Coal During the Smoking Cycle; Beitr. Tabakforsch. Int. 11 (1981) $1-17$.

58. R.J. Reynolds Tobacco Company: Chemical and Biological Studies on New Cigarette Prototypes that Heat Instead of Burn tobacco; R.J. Reynolds Company, Winston-Salem, NC, USA, 1988.

59. Roemer, E., R. Stabbert, K. Rustemeier, D.J. Veltel, T.J. Meisgen, W. Reininghaus, R.A. Carchman, C.L. Gaworski, and K.F. Podraza: Chemical Composition, Cytotoxicity, and Mutagenicity of Smoke from U.S. Commercial and Reference Cigarettes Smoked Under Two Sets of Machine Smoking Conditions; Toxicology 195 (2004) 31-52.

60. SAS Institute Inc.: SAS/STAT® version 9.1 User's Guide; SAS Institute Inc., Cary, NC, USA, 2004.

61. Gori, G.B. and C.J. Lynch: Analytical Cigarette Yields as Predictors of Smoke Bioavailability; Regul. Toxicol. Pharm. 5 (1985) 314-326.

62. Curran, J.G. and J.E. Keifer: A Method for Measuring the Elution of Nicotine and Total Particulate Matter From a Cigarette Filter; Beitr. Tabakforsch. 7 (1973) 29-35.

63. Norman, A.: Cigarette Design and Materials; in: Tobacco: Production, Chemistry, and Technology, edited by D.L Davis and M.T. Nielsen, Blackwell Science, Oxford, 1999, pp. 353-387.

64. Norman, V.: The Effect of Perforated Tipping Paper on the Yield of Various Smoke Components; Beitr. Tabakforsch. 7 (1974) 282-287.

65. Cahours, X., T. Verron, and S. Purkis: Effect of Sugar Content on Acetaldehyde Yield in Cigarette Smoke; Beitr. Tabakforsch. Int. 25 (2012) 381-395.

66. Purkis, S.W., C. Mueller, M. Intorp, and H. Seidel: The Influence of Cigarette Designs and Smoking Regimes on Vapour Phase Yields; Beitr. Tabakforsch. Int. 24 (2010) 33-46.

67. Hammond, D., G.T. Fong, K.M. Cummings, R.J. O’Connor, G.A. Giovino, and A. McNeill: Cigarette Yields and Human Exposure: A Comparison of Alternative Testing Regimens; Cancer Epidemiol. Biomarkers Prev. 15 (2006) 1495-1501.

68. Marian, C., R.J. O’Connor, M.V. Djordjevic, V.W. Rees, D.H. Hatsukami, and P.G. Shields: Reconciling Human Smoking Behavior and Machine Smoking Patterns: Implications for Understanding Smoking 
Behavior and the Impact on Laboratory Studies; Cancer Epidemiol. Biomarkers Prev. 18 (2009) 3305-3320.

69. Urban, H.J., W. Gomm, and M. Schorp: A Modelling Approach to Develop Machine Smoking Protocols Reflecting Human Puffing Behaviour for Conventional Cigarettes; Beitr. Tabakforsch. Int. 23 (2008) 8-18.

70. Harris, J.E.: Smoke Yields of Tobacco-Specific Nitrosamines in Relation to FTC Tar Level and Cigarette Manufacturer: Analysis of the Massachusetts Benchmark Study; Public Health Reports 116 (2001) 336-343.

Corresponding author:

Michael J. Morton

Altria Client Services Inc. 601 E. Jackson

Richmond, VA 23219, USA

E-mail: Michael.J.Morton@altria.com

orSciencePublications@altria.com 